\title{
Stress Induces Supersensitivity of a Cholinergic System in Rats
}

\author{
Steven C. Dilsaver, R. Michael Snider, and Norman E. Alessi
}

\section{Introduction}

Cholinergic system supersensitivity may be involved in the pathophysiology of depressive disorders (Janowsky et al. 1972; Dilsaver and Greden 1984; Dilsaver 1986). Associations between stressful events and onset of depressive (Lloyd 1980) and manic (Kennedy et al. 1983) episodes are documented. Janowsky et al. (1983) proposed that stress increases the sensitivity of central cholinergic mechanisms and that the latter mediates some neurobiological effects of stress. Despite these points, animal models linking the physiologies of depression, mania, stress, and cholinergic systems are not available.

Thermoregulation is subject to muscarinic cholinergic control at the hypothalamic level (Lomax et al. 1964). Lomax and Jenden (1966) reported that oxotremorine produces dose-dependent hypothermia in rats. We utilized this fact to evaluate the effect of stress on a central muscarinic receptor mechanism.

From the Clinical Studies Unit for Affective Disorders (S.C.D.), the Department of Psychiatry (S.C.D., N.E.A.), and the Neuroscience Laboratory (S.C.D., R.M.S.), University of Michigan, Ann Arbor, MI.

Supported in part by Physician Scientist Development Award grants SRC IK11 MH0055301 (S.C.D.) and NS 20920 (R.M.S.).

Address reprint requests to Dr. Steven C. Dilsaver, Department of Psychiatry, Neuroscience Laboratory, 1103 East Huron Drive, Ann Arbor, MI 48104.

Received December 10, 1985; revised February 26, 1986.

\section{Methods}

\section{Temperature Measurement}

Thermosensors (Mini-Mitter Co., Sun River, OR) were implanted into the intraperitoneal cavity. The thermosensors emit hertzian waves at a rate proportional to temperature. A transistor radio set to an AM frequency served as a receiver. Time to emit 25 sounds or "clicks" was measured using a digital display stopwatch. This measure was converted to temperature using a linear regression equation, which was derived by measuring the emission rate of the thermosensors at three temperatures in a temperaturecontrolled water bath. This instrument allows the accurate detection of a change in temperature of $0.1^{\circ} \mathrm{C}$. Details pertaining to the calibration and use of the thermosensor are available elsewhere (Tocco-Bradly et al. 1985).

\section{Oxotremorine Challenge}

All oxotremorine challenges were conducted between 11:00 AM and 2:00 PM and were preceded by the administration of methylscopolamine nitrate, $1 \mathrm{mg} / \mathrm{kg}$ ip, to block the peripheral effects of oxotremorine. Baseline temperature (i.e., time to the 25th "click") was measured 30 min later. Oxotremorine (base), $1 \mathrm{mg} / \mathrm{kg}$ ip, was then given and temperature recorded every $15 \mathrm{~min}$ for 120 min. 


\section{Swim Stress}

Stress sessions started 5 days after thermosensor implantation. Swim stress, a widely accepted means of stressing rats (Weiss et al. 1981), was employed. Sessions were held morning and evening.

The duration of the sessions and water temperature were adjusted so as to produce exhaustion. Extreme fatigue caused the animals to sink. Observation that one or two did struggle to the surface terminated a session.

The first four sessions were at $22-24^{\circ} \mathrm{C}$ for 7,10 , and $15 \mathrm{~min}$, respectively. Sessions 5 and 6 were both $8 \mathrm{~min}$ at $16-17^{\circ} \mathrm{C}, 7$ and 8 lasted $7-9$ min at $8-9^{\circ} \mathrm{C}$, and sessions 9 and 10 for $6-7$ min at 11 and $13^{\circ} \mathrm{C}$. respectively.

\section{Experimental Design}

The study was divided into three phases, as depicted in Figure 1. Phase one (implantation): Five male Sprague-Dawley rats $[301 \pm 6.8 \mathrm{~g}$ (mean \pm SEM)] participated in all phases of the experiment. The first (I) of five oxotremorine challenges marked the end of Phase I and provided a baseline against which subsequent data from challenges could be evaluated. Phase two (stress): This phase started with the first of 10 swim stress sessions and ended with the last session. During this phase, oxotremorine challenges (II, III) were administered. Challenge II followed the fourth stress session by $2 \mathrm{hr}$ on day 8 , and challenge 111 followed the 10th and final stress session by 4 hr on day 10 . Phase III (recovery): During this 8 -day period, the ani- mals were not stressed. Challenge IV occurred on day $12,48 \mathrm{hr}$ after the last stress. The fifth challenge followed in 6 days on day 18 .

Magnitude of the change in body temperature between oxotremorine challenges was the dependent variable. Data were analyzed using Analysis of Variance (ANOVA) with repeated measures

\section{Results}

Swim stress produced increased sensitivity to the hypothermic effects of oxotremorine for at least $52 \mathrm{hr}$ after the last swim session (Figure 2). Oxotremorine challenge II, which followed four swim sessions, did not disclose supersensitivity. However, there was a significant effect (increase in responsiveness to oxotremorine) following 6 more sessions, suggesting that chronic stress resulted in cholinergic supersensitivity ( 1 versus III, $p=0.0049$; II versus III. $p=0.0014$; and I and II versus III, $p=0.0003$ ). Supersensitivity persisted for at least $52 \mathrm{hr}$ (I versus IV, $p=0.019$ ), but a sufficient lapse of time resulted in a loss of supersensitivity (I versus $\mathrm{V}, \mathrm{NS}$ ). This indicates that a poststress recovery occurs within 8 days of the final stress session.

Table 1 highlights the strength of the effect of swim stress on oxotremorine-induced hypothermia. Every animal demonstrated significant increases in its hypothermic responses $4 \mathrm{hr}$ after the last stress session, and four of five did after $52 \mathrm{hr}$. Thus, idiosyncratic responses by one or two animals did not determine the outcome of the study.

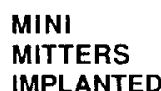

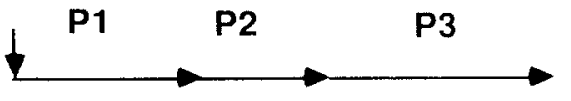

DAYS STRESS AM PM

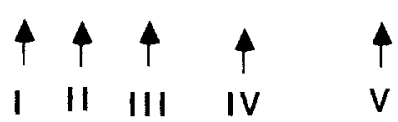

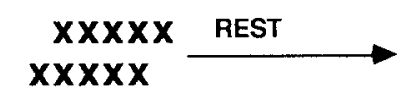

18 sign. Phase one (P1) (implantation), days 0-6, oxotremorine challenge I; Phase two (P2) (stress), days 6-9, oxotremorine challenges II and III; Phase three (P3) (recovery), days $10-18$, oxotremorine challenges IV and $\mathrm{V}$. 


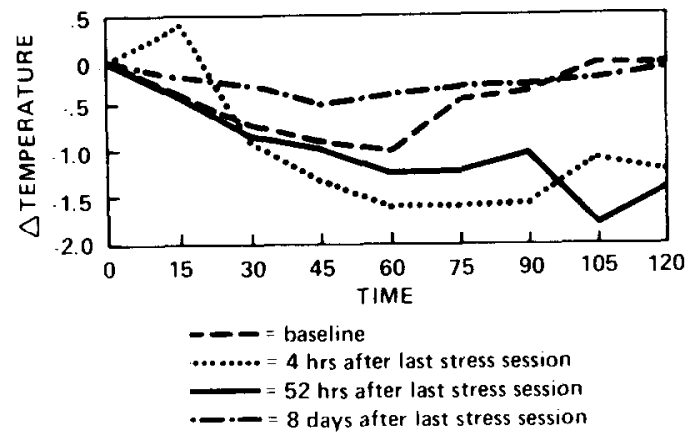

Figure 2. Presentation of hypothermic response to oxotremorine $(1 \mathrm{mg} / \mathrm{kg})$ as a function of time (I) before stress, (II) $2 \mathrm{hr}$ after the fourth stress session, (III) $4 \mathrm{hr}$ after the 10th stress session, (IV) $52 \mathrm{hr}$ after the 10th stress session, and (V) 8 days (or $\sim 196 \mathrm{hr}$ ) after the last stress session. Data were analyzed using ANOVA with repeated measures. I versus II (NS); I versus III $(p=0.0049)$; II versus III $(p=0.0014)$; I versus IV ( $p=0.0019)$, and I versus V (NS). Stress produces significant increases in the sensitivity to oxotremorine, which decays over time.

Table 1. Baseline Hypothermic Response to Challenge with Oxotremorinc ( $1 \mathrm{mg} / \mathrm{kg}$ ip) minus Response after the Last of 10 Stress Sessions

\begin{tabular}{|c|c|c|c|c|}
\hline Rat & $\begin{array}{l}\Delta \text { Mean temperature } \\
\text { change }\left({ }^{\circ} \mathrm{C}\right) \text { at } \\
\text { each time point } \\
\text { relative to the } \\
\text { prestress baseline } \\
\text { (mean } \pm \text { SEM) }\end{array}$ & df & $t$ & $p$ \\
\hline \multicolumn{5}{|c|}{$\begin{array}{l}4 \mathrm{hr} \text { after Last Stress } \\
\text { Session }\end{array}$} \\
\hline 1 & $-1.02 \pm 0.25$ & 7 & -3.995 & 0.005 \\
\hline 2 & $-1.26 \pm 0.25$ & 7 & -2.88 & 0.014 \\
\hline 3 & $-0.46 \pm 0.15$ & 7 & -3.10 & 0.017 \\
\hline 4 & $-0.64 \pm 0.20$ & 7 & -3.18 & 0.016 \\
\hline 5 & $-1.3 \pm 0.27$ & 7 & -4.78 & 0.02 \\
\hline \multicolumn{5}{|c|}{$\begin{array}{l}52 \mathrm{hr} \text { after Last Stress } \\
\text { Session }\end{array}$} \\
\hline 1 & $-0.99 \pm 0.16$ & 7 & -6.10 & 0.0005 \\
\hline 2 & $-0.76 \pm 0.25$ & 7 & -3.09 & 0.0185 \\
\hline 3 & $-1.27 \pm 0.43$ & 7 & -2.94 & 0.022 \\
\hline 4 & $-0.24 \pm 0.08$ & 7 & -0.29 & NS \\
\hline 5 & $-0.93 \pm 0.11$ & 7 & -8.2 & 0.0001 \\
\hline
\end{tabular}

Chronic stress produced a robust increase in the hypothermic response to oxotremorine in 5 rats $4 \mathrm{hr}$ after the final (10th) session. This persisted for at least $52 \mathrm{hr}$ in 4 of 5 animals.

These means were derived by subtracting the temperature changes at $15,30,45,60,75,90,105$, and $120 \mathrm{~min}$ after injection of oxotremorine at baseline and after chronic stress (points III and IV in Figure 1).

\section{Discussion}

To our knowledge, these results are the first experimental evidence that stress sensitizes a central muscarinic mechanism. This could be of importance in the spheres of stress and affective disorders research where cholinoceptor supersensitivity might be a bridge or link between phenomena clinicians have long regarded as related. Further, they suggest that swim stress may provide an animal model of cholinergic system supersensitivity that is useful in affective disorders research. These data may be relevant to neuroendocrine changes in chronically stressed animals. Cholinergic agonists induce the release of adrenocorticotrophic hormone (ACTH) from pituitary explants (Hillhouse et al. 1975). Implantation of atropine crystals into the hypophysis blocks stress-induced secretion of cortisol (Kapanski and Smelik 1973). Nemeroff (1985) recently reported that stress produces the release of corticotropin-releasing factor (CRF) in vivo. It is conceivable that stress mobilizes a cholinergic mechanism that activates the hypothalamic-pituitary-adrenal axis.

Cholinergic dysfunction may be involved in the pathophysiology of depression (Janowsky et al. 1972). Stresses increase the probability that an affective disorder patient will become depressed (Lloyd 1980) or manic (Kennedy et al. 1983). A capacity of stress to activate cholinergic pathways might contribute to this.

There are limitations to a study involving five animals; although the effects of stress were robust and consistent, replication using not only swim stress, but also other forms of stress, will now be required.

\section{References}

Dilsaver SC (1986): Pharmacologic induction of cholinergic system supersensitivity in affective disorders research. J Clin Psychopharmacol 6:65-74.

Dilsaver SC, Greden JF (1984): Antidepressant withdrawal-induced activation (hypomania and mania): Mechanism and theoretical significance. Brain Res $\operatorname{Rev} 7: 29-48$.

Hillhouse EW, Burden J, Jones MT (1975): The effects of various putative neurotransmitters on the 
release of corticotropin releasing hormone from the hypothalamus of the rat in vitro, I. The effect of acetylcholine and noradrenaline. Neuroendocrinology 17:1-11.

Janowsky DS, El-Yousef MK. Davis JM, et al (1972): A cholinergic adrenergic hypothesis of mania and depression. Lancet ii:632-635.

Janowsky DS, Risch SC, Huey L, Judd L, Rousch J (1983): Central physostigmine-induced cardiovascular and behavioral changes: Toward an acetylcholine hypothesis of stress. Psychopharmacol Bull 19:675-682.

Kapanski, Smelik (1973): Analysis of the inhibition of the ACTH release by hypothalamic implants of atropine. Acta Endocrinol 73:651-659.

Kennedy S, Thompson R, Stancer HC, Roy A, Persad E (1983): Life events precipitating mania. $\mathrm{Br}$ $J$ Psvchiatry 142:398-403.

Lloyd C (1980): Life events and depressive disorder: II. Events as precipitating factors. Arch Gen Psychiatry 37:541-548.

Lomax P, Jenden DJ (1966): Hypothermia following systematic and intracerebral injection of oxotremorine in the rat. Neuropharmacology 5:353-359.
Lomax P, Foster RF, Kirkpatrick WW (1964): Cholinergic and adrenergic interactions in the thermoregulatory centers of the rat Brain Re. $15: 431-438$.

Nemeroff CB (1985): The neurobiology of corticotropin-releasing factor: Implications for affective disorders. American College of Neuropsychopharmacology, Maui. 1985.

Risch SC. Cohen PM, Janowsky DS, et al (1981) Physostigmine induction of depressive symptom. atology in normal human subjects. $J$ Psychiatr Res 4:89-94.

Tocco-Bradley R, Kluger MJ. Kauffman CA (1985). Effect of age on fever: An acute-phase response of rats to endotoxin and Salmonella typhimurium. Infect Immun 47:106-111.

Weiss JM, Goodman PA, Losito BG, Corrigan S, Charry JM. Bailey WH (1981): Behavioral depression produced by an uncontrollable stressor: Relationship to norepinephrine, dopamine and se. rotonin levels in various regions of rat brain. Brain Res Rev 3:161-205. 